\title{
TNF- $\alpha$ treatment increases DKK1 protein levels in primary osteoblasts via upregulation of DKK1 mRNA levels and downregulation of miR-335-5p
}

\author{
SHANSHAN LI ${ }^{1,2}$, YIXIN YIN ${ }^{1,3}$, LIPING YAO ${ }^{4}$, ZIYI LIN $^{1}$, SHENGJUN SUN $^{1}$, JIN ZHANG $^{1}$ and XIAOYAN LI ${ }^{1}$ \\ ${ }^{1}$ Department of Endodontics, School and Hospital of Stomatology, Cheeloo College of Medicine, \\ Shandong University and Shandong Key Laboratory of Oral Tissue Regeneration and Shandong Engineering Laboratory \\ for Dental Materials and Oral Tissue Regeneration, Jinan, Shandong 250012; ${ }^{2}$ Dental Department, \\ Huaihe Hospital of Henan University, Kaifeng, Henan 475000; ${ }^{3}$ Oral Implantology Center, Ji Nan Stomatology Hospital, \\ Jinan, Shandong 250001; ${ }^{4}$ Department of Endodontics, Yantai Stomatological Hospital, Yantai, Shandong 264008, P.R. China
}

Received January 8, 2020; Accepted April 28, 2020

DOI: $10.3892 / \mathrm{mmr} .2020 .11152$

\begin{abstract}
Elucidation of the underlying mechanisms governing osteogenic differentiation is of significant importance to the improvement of therapeutics for bone-related inflammatory diseases. Tumor necrosis factor- $\alpha(\mathrm{TNF}-\alpha)$ is regarded as one of the major agents during osteogenic differentiation in an inflammatory environment. miR-335-5p post-transcriptionally downregulates the Dickkopf WNT signaling pathway inhibitor 1 (DKK1) protein level by specifically binding to the DKK1 3'UTR and activating Wnt signaling. The role of miR-335-5p in TNF- $\alpha$-induced post-transcriptional regulation of DKK1 remains to be elucidated. In the present study, the mRNA and protein levels of DKK1 and the level of miR-335-5p were determined in MC3T3-E1 cells and the primary calvarial osteoblasts treated with or without TNF- $\alpha$. The role of NF- $\kappa B$ signaling in TNF- $\alpha$-induced post-transcriptional regulation of DKK1 was also evaluated. The present study determined that although TNF- $\alpha$ treatment exhibited cell-specific effects on DKK1 mRNA expression, the stimulation of TNF- $\alpha$ time- and concentration-dependently upregulated the protein levels of DKK1. In primary calvarial osteoblasts, the decreased miR-335-5p level induced by TNF- $\alpha$-activated $\mathrm{NF}-\kappa \mathrm{B}$ signaling served an important role in mediating the post-transcriptional regulation of DKK1 by TNF- $\alpha$ treat-
\end{abstract}

Correspondence to: Dr Xiaoyan Li, Department of Endodontics, School and Hospital of Stomatology, Cheeloo College of Medicine, Shandong University and Shandong Key Laboratory of Oral Tissue Regeneration and Shandong Engineering Laboratory for Dental Materials and Oral Tissue Regeneration, 44-1 Wenhua Road West, Jinan, Shandong 250012, P.R. China

E-mail: lixiaoyanwhu@sdu.edu.cn

Key words: tumor necrosis factor- $\alpha$, Dickkopf WNT signaling pathway inhibitor $1, \mathrm{NF}-\mathrm{\kappa B}$ signaling, miR-335-5p, primary osteoblasts, MC3T3-E1 cells, post-transcriptional regulation ment. In MC3T3-E1 cells, the post-transcriptional regulation of DKK1 by TNF- $\alpha$ treatment was more complicated and involved other molecular signaling pathways in addition to the $\mathrm{NF}-\kappa \mathrm{B}$ signaling. In conclusion, $\mathrm{TNF}-\alpha$ treatment served an important role in the post-transcriptional regulation of DKK1 expression, which requires further investigation. The results of the present study not only provided new insights into the regulatory effects of miR-335-5p on osteogenic differentiation in an inflammatory microenvironment, but may also promote the development of potential therapeutic strategies for the treatment of bone-related inflammatory diseases.

\section{Introduction}

Chronic inflammation is involved in the pathological processes of various bone diseases including ankylosing spondylitis, osteoporosis, periodontitis and peri-implantitis (1-3). In these inflammatory bone diseases, impaired osteoblast differentiation and bone formation significantly contribute to the imbalanced bone metabolism (4). As a pleiotropic proinflammatory cytokine, tumor necrosis factor- $\alpha$ (TNF- $\alpha)$ is regarded as one of the major factors in the regulatory network of bone-related inflammatory diseases (5). On binding to its receptors, TNF- $\alpha$ activates sequential signaling cascades and promotes the nuclear translocation of $\mathrm{NF}-\kappa \mathrm{B}$, which subsequently mediates the transcription of the downstream target genes (6). (E)3-[(4-methylphenyl)-sulfonyl]-2-propenenitrile (BAY 11-7082), is an irreversible inhibitor of TNF- $\alpha$-induced I $\mathrm{B}-\alpha$ phosphorylation, and is widely used to inactivate $\mathrm{NF}-\kappa \mathrm{B}$ signaling (7-10). TNF- $\alpha$ displays contradictory and complex effects on osteoblast differentiation and bone formation, depending upon the local microenvironment and concentration of TNF- $\alpha(4,11)$. The regulatory effect of TNF- $\alpha$ on bone formation can be, at least in part, mediated by its inhibitory effect on the canonical Wnt signaling (12). The canonical Wnt signaling actively participates in the regulation of osteoblast proliferation, apoptosis and differentiation, and the genetic deletion of $\beta$-catenin results in the absence of skeletal structures and the arrest of osteoblast differentiation (13). As one 
of the extracellular antagonists of canonical Wnt signaling, Dickkopf WNT signaling pathway inhibitor 1 (DKK1) inactivates canonical Wnt signaling and disrupts osteogenic differentiation by binding to the receptors of Wnt proteins (14). As a result, DKK1 serves a pivotal role in sustaining proper skeletal homeostasis and regulating bone remodeling. In estrogen deficiency-induced osteoporosis, TNF- $\alpha$ was revealed to suppress bone formation via suppression of Wnt/3-catenin signaling (15). In addition, the inhibitory effect of TNF- $\alpha$ on canonical Wnt signaling can be mediated by enhanced expression of the Wnt antagonists DKK1 and sclerostin (SOST) (16).

MicroRNAs (miRNAs) are a group of small non-coding RNAs that post-transcriptionally regulate gene expression by binding to specific sequences in the 3'UTR of target genes and induce either translational repression or cleavage of the target mRNAs (17). Studies have revealed that miRNAs are key regulators in mediating TNF- $\alpha$-induced inflammatory responses. For example, miR-218 has been revealed to target tumor necrosis factor receptor 1 (TNFR1) and suppress the NF- $\kappa B$ signaling pathway $(18,19)$. TNF- $\alpha$ was also revealed to enhance the expression of miR-23b and miR-33a-5p, which in turn downregulated the levels of Runt-related transcription factor 2 (Runx2) and special AT-rich sequence-binding protein 2 (SATB2), respectively, and therefore hindered osteogenic differentiation $(20,21)$. miRNAs also actively participate in the crosstalk between canonical Wnt signaling TNF- $\alpha$ signaling $(2,22)$. In human fetal osteoblastic cells, miR-29a activated the canonical Wnt signaling by targeting Wnt antagonists DKK1 and GSK3 $\beta$, and the downregulation of miR-29a by TNF- $\alpha$ indicated that miR-29a plays a role in TNF- $\alpha$-mediated osteogenic inhibition (22). In our previous studies, it was determined that miR-335-5p activated Wnt signaling and promoted osteogenic differentiation by downregulating the protein levels of DKK1 $(13,23)$. However, it remains to be elucidated whether the post-transcriptional regulation of DKK1 by miR-335-5p also plays a role in an inflammatory microenvironment.

To investigate the effect of TNF- $\alpha$ on the post-transcriptional regulation of DKK1 by miR-335-5p in MC3T3-E1 murine osteoblast-like cells and primary calvarial osteoblasts, the effect of TNF- $\alpha$ on the mRNA and protein levels of DKK1 in these cells was investigated. The expression levels of miR-335-5p upon TNF- $\alpha$ stimulation were then determined. Changes in the functions of miR-335-5p in an inflammatory microenvironment were also evaluated. It was determined that although TNF- $\alpha$ treatment exhibited cell-specific effects on DKK1 mRNA expression, the stimulation of TNF- $\alpha$ time- and concentration-dependently upregulated the protein levels of DKK1, indicating that TNF- $\alpha$ treatment played an important role in the post-transcriptional regulation of DKK1 expression.

\section{Materials and methods}

Animals. C57BL/6 mice (6 male and 6 female, 4-6-day-old, weight 2-4 g), were obtained from Shandong University Laboratory Animal Center (Jinan, China). The animals were immediately sacrificed for getting primary calvarial osteoblasts. The animals were used in accordance with the guidelines developed by the Animal Care and Use Committee of the School of Dentistry, Shandong University (https://www. qlyxb.sdu.edu.cn/info/1103/4118.htm; SDYZ-[2018]-06) Jinan, China. Ethical approval for the animal experiments was obtained by The Medical Ethics Committee of the School of Stomatology, Shandong University (protocol no. 20180602).

Cell culture and reagents. MC3T3-E1 murine osteoblast-like cells were purchased from the Cell Bank of Chinese Academy of Sciences. The cells were maintained in $\alpha$-minimum essential medium ( $\alpha$-MEM; HyClone; GE Healthcare life Sciences) containing $10 \%(\mathrm{v} / \mathrm{v})$ fetal bovine serum (FBS; Biological Industries), $100 \mathrm{U} / \mathrm{ml}$ penicillin and $100 \mu \mathrm{g} / \mathrm{ml}$ streptomycin (both from Beijing Solarbio Science \& Technology Co., Ltd.). As previously described (13), primary calvarial osteoblasts were isolated from C57BL/6 mice by enzymatic digestion and cultured in the same medium as that used for MC3T3-E1 cells.

Briefly, the calvaria bone was isolated from 4-6-day-old C57BL/6 mice, gently separated and cut into small pieces. The tissue was then digested with $0.1 \%$ type I collagenase and $0.25 \%$ trypsin at $37^{\circ} \mathrm{C}$ for $20 \mathrm{~min}$. The digestion procedure was repeated 5 times, and cell suspensions of the last 4 digestions were collected. The cells were centrifuged $(500 \mathrm{x} \mathrm{g}, 10 \mathrm{~min}$, $20^{\circ} \mathrm{C}$ ), re-suspended and cultured in a $37^{\circ} \mathrm{C}$ sterile incubator containing $5 \% \mathrm{CO}_{2}$.

Recombinant murine TNF- $\alpha$ was purchased from PeproTech, Inc. BAY 11-7082 was obtained from Beyotime Institute of Biotechnology.

To assess whether DKK1 and miR-335-5p participate in the effects of specific inflammatory stimuli, MC3T3-E1 cells and primary calvarial osteoblasts were exposed to TNF- $\alpha$ for different time-points and concentrations. For time-response assay, cells were exposed to $15 \mathrm{ng} / \mathrm{ml} \mathrm{TNF}-\alpha$ for $0,12,24$ and $48 \mathrm{~h}$. For concentration-response assay, cells were treated with TNF- $\alpha(0,15$ or $50 \mathrm{ng} / \mathrm{ml})$ for $48 \mathrm{~h}$. For signal pathway investigation, TNF- $\alpha(15 \mathrm{ng} / \mathrm{ml})$ was added to the medium with or without the NF- $\mathrm{kB}$ signal pathway inhibitor BAY11-7082 $(1 \mu \mathrm{M})$ for $48 \mathrm{~h}$.

Reverse transcription-quantitative ( $R T-q) P C R$. Following the manufacturer's instructions, total RNA was extracted from cells $\left(1 \times 10^{6}\right)$ using TRIzol $^{\circledR}$ reagent (Invitrogen; Thermo Fisher Scientific, Inc.), and reverse-transcribed into cDNA using PrimeScript $^{\mathrm{TM}}$ RT Reagent Kit with gDNA Eraser (Takara Bio, Inc.). RT-qPCR was performed using the LightCycler480 SYBR Green I Master mix (Roche Diagnostics) on a Roche 480 Lightcycler (Roche Diagnostics). The thermocycling conditions were $94^{\circ} \mathrm{C}$ for $5 \mathrm{~min}$, followed by 40 cycles of $95^{\circ} \mathrm{C}$ for $10 \mathrm{sec}, 60^{\circ} \mathrm{C}$ for $20 \mathrm{sec}$ and $72^{\circ} \mathrm{C}$ for $20 \mathrm{sec}$. The primer sequences were: DKK1, forward: 5'-CTCATCAATTCCAAC GCGATCA-3' and reverse: 5'-GCCCTCATAGAGAACTCC CG-3'; GAPDH, forward: 5'-AGGTCGGTGTGAACGGAT TTG-3' and reverse: 5'-TGTAGACCATGTAGTTGAGGT CA-3' (synthesized by Invitrogen; Thermo Fisher Scientific, Inc.). The relative gene expression levels were evaluated by the $2^{-\Delta \Delta C q}$ method (24), with GAPDH serving as an internal control. Each sample was prepared in triplicate, and each experiment was repeated at least three times.

Western blot analysis. Whole protein lysates were extracted from cells with Radio Immunoprecipitation Assay (RIPA) lysis buffer (Beijing Solarbio Science \& Technology Co., 
Ltd.) containing 1\% phenylmethanesulfonyl fluoride (PMSF; Beyotime Institute of Biotechnology) The concentrations of the protein lysates were determined using the BCA Protein Assay kit (Beyotime Institute of Biotechnology). The protein lysates were then mixed with $5 \mathrm{X}$ loading buffer (Beyotime Institute of Biotechnology) at $100^{\circ} \mathrm{C}$ for $5 \mathrm{~min}$, and $25 \mu \mathrm{g}$ protein from each sample were run on $10 \%$ sodium dodecyl sulfate polyacrylamide electrophoresis gel (Beyotime Institute of Biotechnology) and electrotransferred to polyvinylidene fluoride membranes (Invitrogen; Thermo Fisher Scientific, Inc.) for $1 \mathrm{~h}$ at $100 \mathrm{~V}$. After blocking in 5\% nonfat-dried milk (BD Biosciences) for $1 \mathrm{~h}$ at room temperature, the membranes were then incubated with primary antibodies overnight at $4^{\circ} \mathrm{C}$ according to the manufacturer's instructions. Mouse monoclonal anti-DKK1 antibody was purchased from Abcam (1:1,000; product code ab61275), and mouse monoclonal anti- $\beta$-actin antibody was purchased from OriGene Technologies, Inc. (1:1,000; cat. no. TA-09). Horseradish Peroxidase linked (HRP-linked) anti-mouse GAPDH antibody (1:20,000; cat. no. HRP-60004) was purchased from ProteinTech Group, Inc. Blots were stripped and reprobed with HRP-labelled goat anti-mouse IgG $(\mathrm{H}+\mathrm{L})$ antibody $(1: 10,000$; cat. no. ZB-2305, OriGene Technologies, Inc.) and HRP-linked anti-mouse GAPDH antibody (1:20,000; cat. no. HRP-60004, ProteinTech Group, Inc) to monitor protein loading. Protein bands were visualized using the Chemiluminescent HRP Substrate (EMD Millipore) on an ECL detection system (SmartChemi 420; Beijing Sage Creation Science Co., Ltd.) with $\beta$-actin or GAPDH serving as an internal control. The relative intensity of each protein band was evaluated using the ImageJ software package v.1.6.0 (National Institutes of Health).

RT-qPCR for miRNA analysis. Total RNA was extracted from cells $\left(1 \times 10^{6}\right)$ using TRIzol ${ }^{\circledR}$ reagent (Invitrogen; Thermo Fisher Scientific, Inc.) and the miRNA was reverse-transcribed into cDNA using the Mir-X ${ }^{\mathrm{TM}}$ miRNA First-Strand Synthesis kit (Takara Bio, Inc.). RT-qPCR was conducted using the SYBR Premix Ex TaqTMII kit (Takara Bio, Inc.). on the aforementioned Roche 480 Lightcycler according to the manufacturer's instructions. The thermocycling conditions were $95^{\circ} \mathrm{C}$ for $15 \mathrm{sec}$, followed by 40 cycles of $95^{\circ} \mathrm{C}$ for $5 \mathrm{sec}, 60^{\circ} \mathrm{C}$ for $20 \mathrm{sec}$ and then $95^{\circ} \mathrm{C}$ for $5 \mathrm{sec}, 55^{\circ} \mathrm{C}$ for $30 \mathrm{sec}$. The primer sequences were: U6, 5'-GGAACGATACAGAGAAGATTAGC-3' and 5'-TGGAACGCTTCACGA ATTTGCG-3'; miR-335-5p: 5'-TCAAGAGCAATAACGAAAAATGT-3' (synthesized by Invitrogen; Thermo Fisher Scientific, Inc.). The mRQ universal primer was obtained using the aforementioned Mir-X ${ }^{\mathrm{TM}}$ miRNA First-Strand Synthesis kit. The relative miR-335-5p expression level was calculated using the $2^{-\Delta \Delta \mathrm{Cq}}$ method (24), with U6 serving as an internal control. Each sample was prepared in triplicate, and each experiment was repeated at least three times.

Cell transfection and luciferase assay. The luciferase reporter construct encoding the 3'UTR of murine DKK1, pMIR-REPORT-DKK1 UTR, was a gift from Dr Jake Chen (Tufts University, Boston, MA, USA) (13). For transient transfection, MC3T3-E1 cells were cultured in 12-well plates at a density of $5 \times 10^{4}$ cells per $\mathrm{ml}$ overnight, and co-transfected with 900 ng pMIR-REPORT-DKK1 UTR and 100 ng pRL-TK Vector (Promega Corporation) using Lipofectamine ${ }^{\circledR} 3000$ reagent (Invitrogen; Thermo Fisher Scientific, Inc.). Cells co-transfected with pMIR-REPORT (900 ng) and pRL-TK $(100 \mathrm{ng})$ served as controls. Then, $6 \mathrm{~h}$ after the co-transfection, the transfection complex was removed and the cells were cultured with fresh, normal medium for another $12 \mathrm{~h}$. Then after exposure to TNF- $\alpha$ for different time-points and concentrations, the cells were harvested and the luciferase levels were monitored using the Dual-Luciferase Assay System (Promega Corporation) on a Centro xs3 LB960 luminometer (Berthold Technologies). The firefly luciferase activity was normalized to the Renilla luciferase activity. Transfected MC3T3-E1 cells were also treated with or without $15 \mathrm{ng} / \mathrm{ml} \mathrm{TNF-} \alpha$ and/or $1 \mu \mathrm{M}$ BAY 11-7082 for $48 \mathrm{~h}$, with untreated cells serving as negative controls, and then the cells were harvested and the luciferase levels were also determined.

pMIR-REPORT-DKK1 UTR and pRL-TK were also co-transfected into the MC3T3-E1 cells with the mmu-miR-335-5p mimic or mirVana ${ }^{\mathrm{TM}}$ miRNA Mimic Negative Control \#1 according to the manufacturer's instructions (30 nM; Ambion; Thermo Fisher Scientific, Inc.). Following treatments with TNF- $\alpha$, the cells were harvested and the luciferase levels were determined as previously described.

Statistical analysis. All results are presented as the mean \pm SEM for at least three replicates. One-way analysis of variance (ANOVA) test with post hoc contrasts by Student-Newman-Keuls test or Student's t-test was used to test the statistical significance using the SPSS 16.0 Software Package (SPSS, Inc.). $\mathrm{P}<0.05$ was considered to indicate a statistically significant difference.

\section{Results}

TNF- $\alpha$ exhibits different effects on DKK1 mRNA expression in different osteoblast lineage cells. MC3T3-E1 cells and primary calvarial osteoblasts were treated with TNF- $\alpha$ for different time durations, and the mRNA levels of DKK1 were determined using RT-qPCR. It was determined that the DKK1 mRNA levels exhibited a time-dependent decrease by TNF- $\alpha$ treatment in MC3T3-E1 cells, while those in primary calvarial osteoblasts exhibited a time-dependent increase (Fig. 1A).

MC3T3-E1 cells and primary calvarial osteoblasts were cultured with different concentrations of TNF- $\alpha$ and the mRNA expression of DKK1 then determined by RT-qPCR. It was revealed that in the MC3T3-E1 cells, the DKK1 mRNA levels demonstrated a concentration-dependent decrease upon TNF- $\alpha$ stimulation, while those in the primary calvarial osteoblasts exhibited a concentration-dependent increase (Fig. 1B).

$T N F-\alpha$ plays a role in the post-transcriptional regulation of DKK1 in both osteoblast lineage cells. MC3T3-E1 cells and primary calvarial osteoblasts were then treated with TNF- $\alpha$ for different concentrations and duration, and the protein levels of DKK1 were determined using western blotting. In contrast to the time- and concentration-dependent decrease in DKK1 mRNA levels after TNF- $\alpha$ treatment in MC3T3-E1 cells, DKK1 protein levels in these cells exhibited a time- and concentration-dependent increase upon TNF- $\alpha$ stimulation. As 

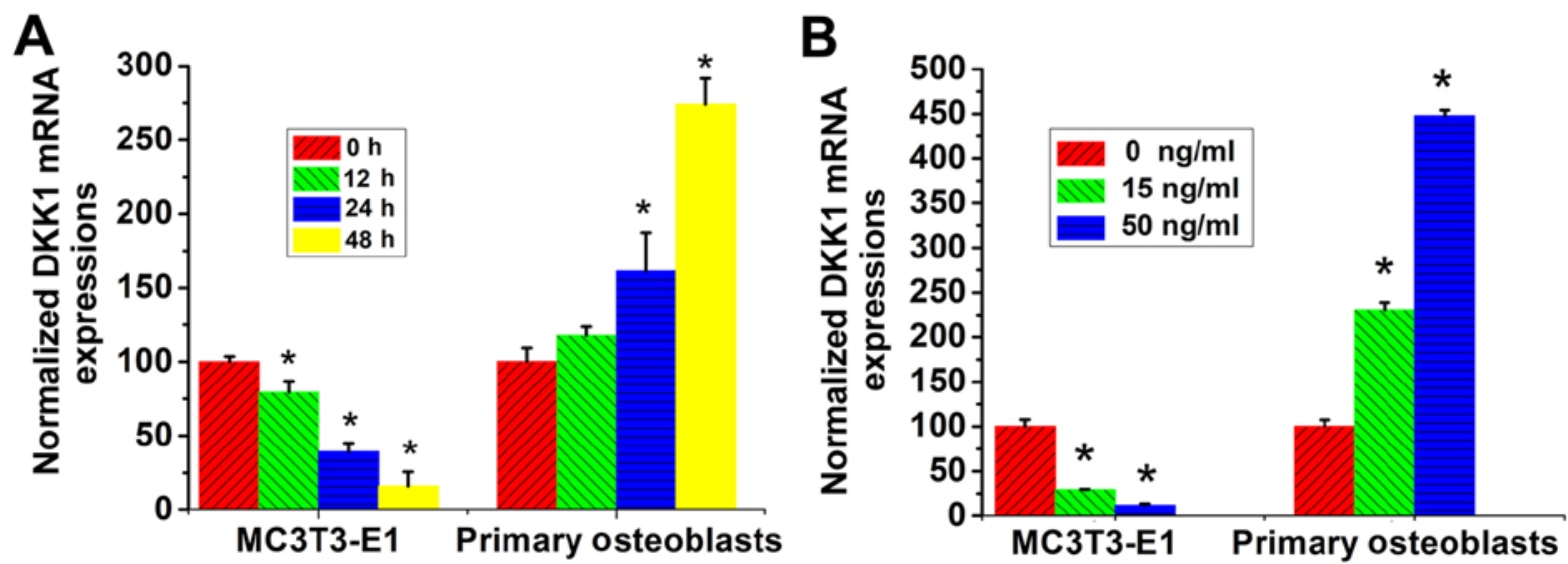

Figure 1. DKK1 mRNA levels in MC3T3-E1 cells and primary calvarial osteoblasts treated with TNF- $\alpha$. (A) DKK1 mRNA levels in MC3T3-E1 cells and primary calvarial osteoblasts treated with $15 \mathrm{ng} / \mathrm{ml} \mathrm{TNF}-\alpha$ for $0,12,24$ and $48 \mathrm{~h}$. ${ }^{~} \mathrm{P}<0.05$ vs. the 0 -h group, $\mathrm{n}=3$. (B) DKK1 mRNA levels in MC3T3-E1 cells and primary calvarial osteoblasts treated with 0,15 and $50 \mathrm{ng} / \mathrm{ml} \mathrm{TNF}-\alpha$ for $48 \mathrm{~h}$. ${ }^{*} \mathrm{P}<0.05$ vs. the $0-\mathrm{ng} / \mathrm{ml}$ group, $\mathrm{n}=3$. DKK1, Dickkopf WNT signaling pathway inhibitor 1 ; TNF- $\alpha$, tumor necrosis factor- $\alpha$.

A
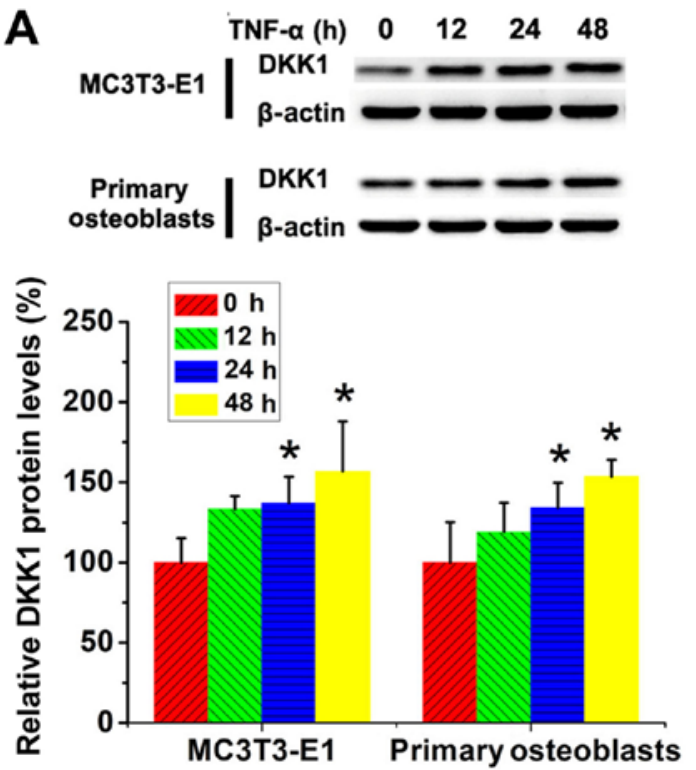
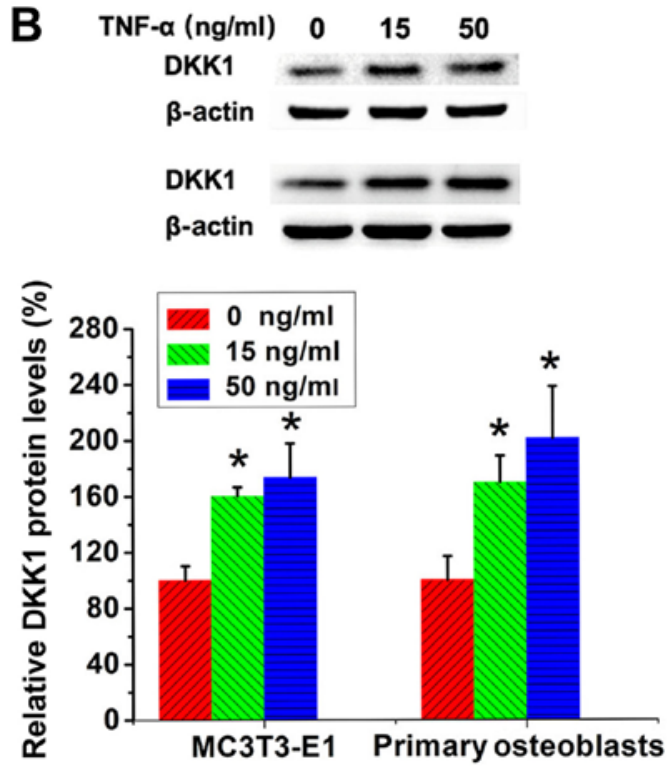

Figure 2. DKK1 protein levels in MC3T3-E1 cells and primary calvarial osteoblasts treated with TNF- $\alpha$. (A) Protein levels of DKK1 in MC3T3-E1 cells and primary calvarial osteoblasts treated with $15 \mathrm{ng} / \mathrm{ml}$ TNF- $\alpha$ for $0,12,24$ and $48 \mathrm{~h}$. ${ }^{*} \mathrm{P}<0.05$ vs. the 0 -h group, $\mathrm{n}=3$. (B) Protein levels of DKK1 in MC3T3-E1 cells and primary calvarial osteoblasts treated with 0,15 and $50 \mathrm{ng} / \mathrm{ml} \mathrm{TNF-} \alpha$ for $48 \mathrm{~h}$. ${ }^{*} \mathrm{P}<0.05$ vs. the 0 -ng/ml group, $\mathrm{n}=3$. DKK1, Dickkopf WNT signaling pathway inhibitor 1 ; TNF- $\alpha$, tumor necrosis factor- $\alpha$.

with the changes in DKK1 mRNA levels in primary calvarial osteoblasts, DKK1 protein levels in these cells also exhibited a time- and concentration-dependent increase. However, the extent of the increase in DKK1 protein levels upon TNF- $\alpha$ treatment was considerably lower than that in DKK1 mRNA levels (Fig. 2A and B).

Regulatory effects of TNF- $\alpha$ treatment on DKK1 protein levels are mediated by $N F-\kappa B$ signaling. MC3T3-E1 cells and primary calvarial osteoblasts were treated with TNF- $\alpha$ and/or BAY 11-7082 for $48 \mathrm{~h}$, with untreated cells serving as negative controls, followed by the determination of the mRNA and protein levels of DKK1. It was determined that BAY 11-7082 treatment partially reversed the regulatory effects of TNF- $\alpha$ on DKK1 mRNA levels in both MC3T3-E1 cells and the primary calvarial cells (Fig. 3A). In addition, BAY 11-7082 treatment completely reversed the positive effects of TNF- $\alpha$ on DKK1 protein levels in both osteoblast lineage cells (Fig. 3B).

$T N F-\alpha$ treatment downregulates the expression of miR-335-5p via different molecular mechanisms in different osteoblast lineage cells.MC3T3-E1 cells and primary calvarial osteoblasts were then treated with TNF- $\alpha$ for different concentrations and duration and the levels of miR-335-5p were determined using RT-qPCR. In both MC3T3-E1 cells and primary calvarial osteoblasts, a time- and concentration-dependent decrease in miR-335-5p expression upon TNF- $\alpha$ stimulation was observed (Fig. 4A and B).

MC3T3-E1 cells and primary calvarial osteoblasts were then treated with TNF- $\alpha$ and/or BAY 11-7082 for $48 \mathrm{~h}$, with 

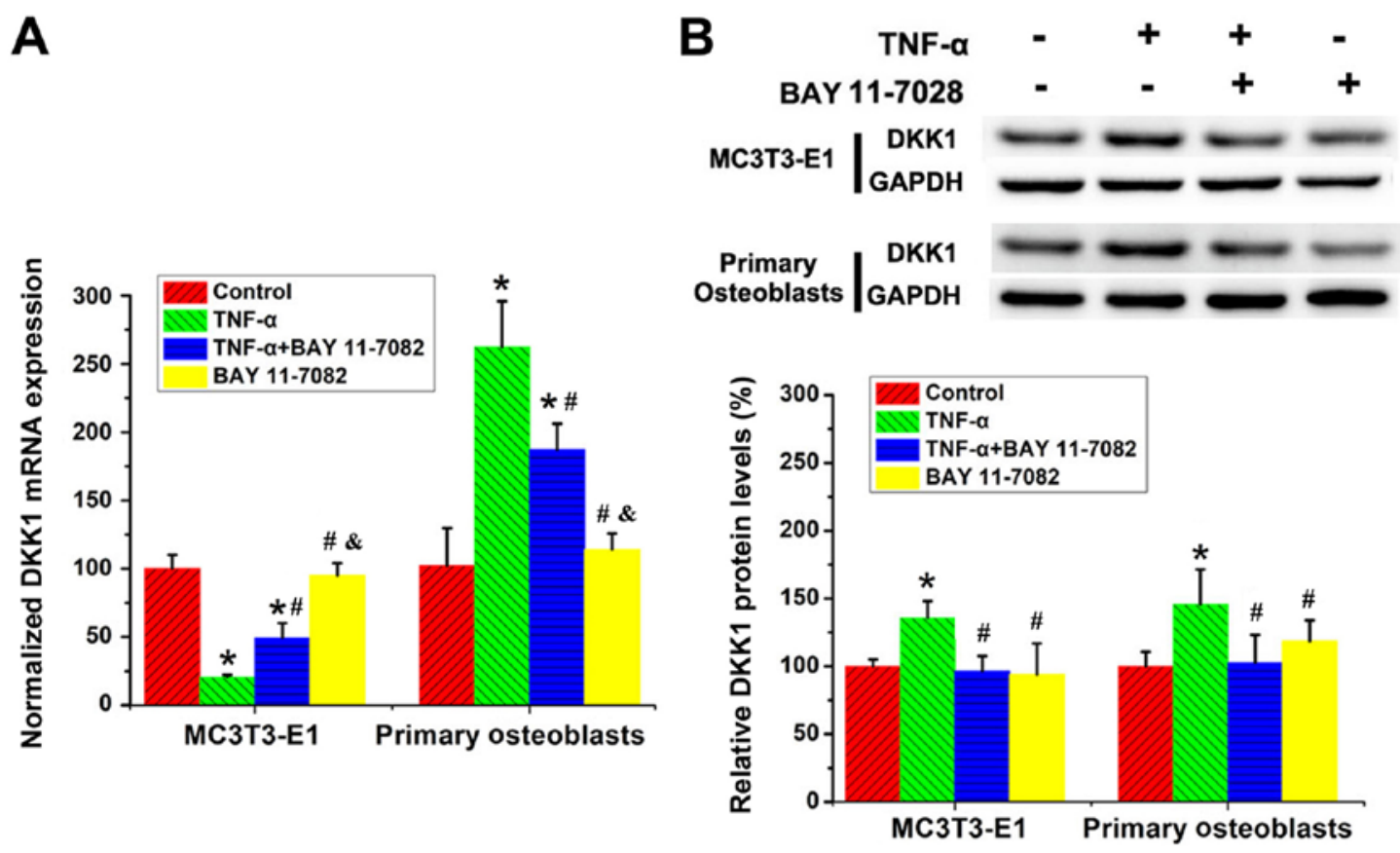

Figure 3. Role of the NF- $\mathrm{kB}$ signaling pathway in mediating TNF- $\alpha$-regulated expression of DKK1 in MC3T3-E1 cells and primary calvarial osteoblasts. MC3T3-E1 cells and primary calvarial osteoblasts were treated with $15 \mathrm{ng} / \mathrm{ml} \mathrm{TNF}-\alpha$ and/or $1 \mu \mathrm{M}$ BAY 11-7082 for $48 \mathrm{~h}$, and the untreated cells served as controls. The DKK1 (A) mRNA levels and (B) protein levels in these cells were determined. ${ }^{*} \mathrm{P}<0.05$ vs. the Control group; ${ }^{*} \mathrm{P}<0.05$ vs. the TNF- $\alpha$ group; ${ }^{\&} \mathrm{P}<0.05$ vs. the TNF- $\alpha+$ BAY 11-7082 group, $\mathrm{n}=3$. TNF- $\alpha$, tumor necrosis factor- $\alpha$; DKK1, Dickkopf WNT signaling pathway inhibitor 1.

untreated cells serving as negative controls, and the expression of miR-335-5p was evaluated. Notably, BAY 11-7082 treatment exhibited no effects on the expression of miR-335-5p in MC3T3-E1 cells, while completely reversing TNF- $\alpha$-induced inhibition of miR-335-5p expression in the primary calvarial cells (Fig. 4C).

TNF- $\alpha$ treatment exhibits no effects on the inhibitory action of miR-335-5p by targeting DKK1 3'UTR. MC3T3-E1 cells were then treated with TNF- $\alpha$ for different concentrations and duration, and the luciferase activities were determined using luciferase assays. The results demonstrated that the insertion of DKK1 3'UTR resulted in a $\sim 30 \%$ reduction in the luciferase activity of MC3T3 cells. Furthermore, TNF- $\alpha$ treatment time- and concentration-dependently reversed the inhibitory effect of the DKK1 3'UTR insertion on luciferase activities (Fig. 5A and B).

pMIR-REPORT-DKK1 UTR and pRL-TK were then co-transfected into the MC3T3-E1 cells with the mmu-miR-335-5p mimic or mirVana ${ }^{\mathrm{TM}}$ miRNA Mimic Negative Control \#1. pMIR-REPORT and pRL-TK were also co-transfected into MC3T3-E1 cells with the mmu-miR-335-5p mimic or mirVana ${ }^{\mathrm{TM}}$ miRNA Mimic Negative Control \#1 to serve as controls. Following transfection, cells were treated with or without $15 \mathrm{ng} / \mathrm{ml} \mathrm{TNF}-\alpha$ for $48 \mathrm{~h}$ and the luciferase levels were determined as described above. Consistent with the results illustrated in Fig. 5A and B, the insertion of DKK1 3'UTR resulted in a $\sim 30 \%$ decrease in the luciferase levels when compared with the corresponding control cells. The co-transfection of pMIR-REPORT-DKK1 UTR with the mmu-miR-335-5p mimic led to an additional $20 \%$ decrease in the luciferase levels, resulting in a total $50 \%$ decrease in the luciferase levels when compared with the control cells co-trans- fected with pMIR-REPORT and the mmu-miR-335-5p mimic. After $48 \mathrm{~h}$ of TNF- $\alpha$ treatment, although MC3T3-E1 cells transfected with pMIR-REPORT-DKK1 UTR exhibited a $20 \%$ decrease when compared with the control cells, no statistically significant difference was detected between these two groups. In addition, in the presence of TNF- $\alpha$, the luciferase levels in MC3T3-E1 cells co-transfected with pMIR-REPORT-DKK1 UTR and the mmu-miR-335-5p mimic were $40 \%$ lower than those in the control cells co-transfected with pMIR-REPORT and the mmu-miR-335-5p mimic (Fig. 5C).

Following transient co-transfection with pMIR-REPORTDKK1 UTR and the pRL-TK Vector, MC3T3-E1 cells were treated with or without $15 \mathrm{ng} / \mathrm{ml} \mathrm{TNF}-\alpha$ and/or $1 \mu \mathrm{M}$ BAY 11-7082 for $48 \mathrm{~h}$. MC3T3-E1 cells co-transfected with pMIR-REPORT and the pRL-TK Vector served as controls. Luciferase activities were determined using luciferase assays as aforementioned. It was determined that $\mathrm{TNF}-\alpha$ treatment alone resulted in a $20 \%$, but not a statistically significant, decrease in luciferase levels when compared with pMIR-REPORT-DKK1 UTR-transfected MC3T3-E1 cells with the control cells. By contrast, treatment with both TNF- $\alpha$ and BAY 11-7082 slightly enhanced the decrease in luciferase levels to $26 \%$, which showed statistical significance, when compared with pMIR-REPORT-DKK1 UTR-transfected MC3T3-E1 cells with the control cells (Fig. 5D).

\section{Discussion}

Bone-related inflammatory diseases are usually associated with impaired osteogenic differentiation and bone formation $(25,26)$. It is of great importance to investigate the underlying mechanisms and promote the development of novel therapeutic techniques. The present study focused on 

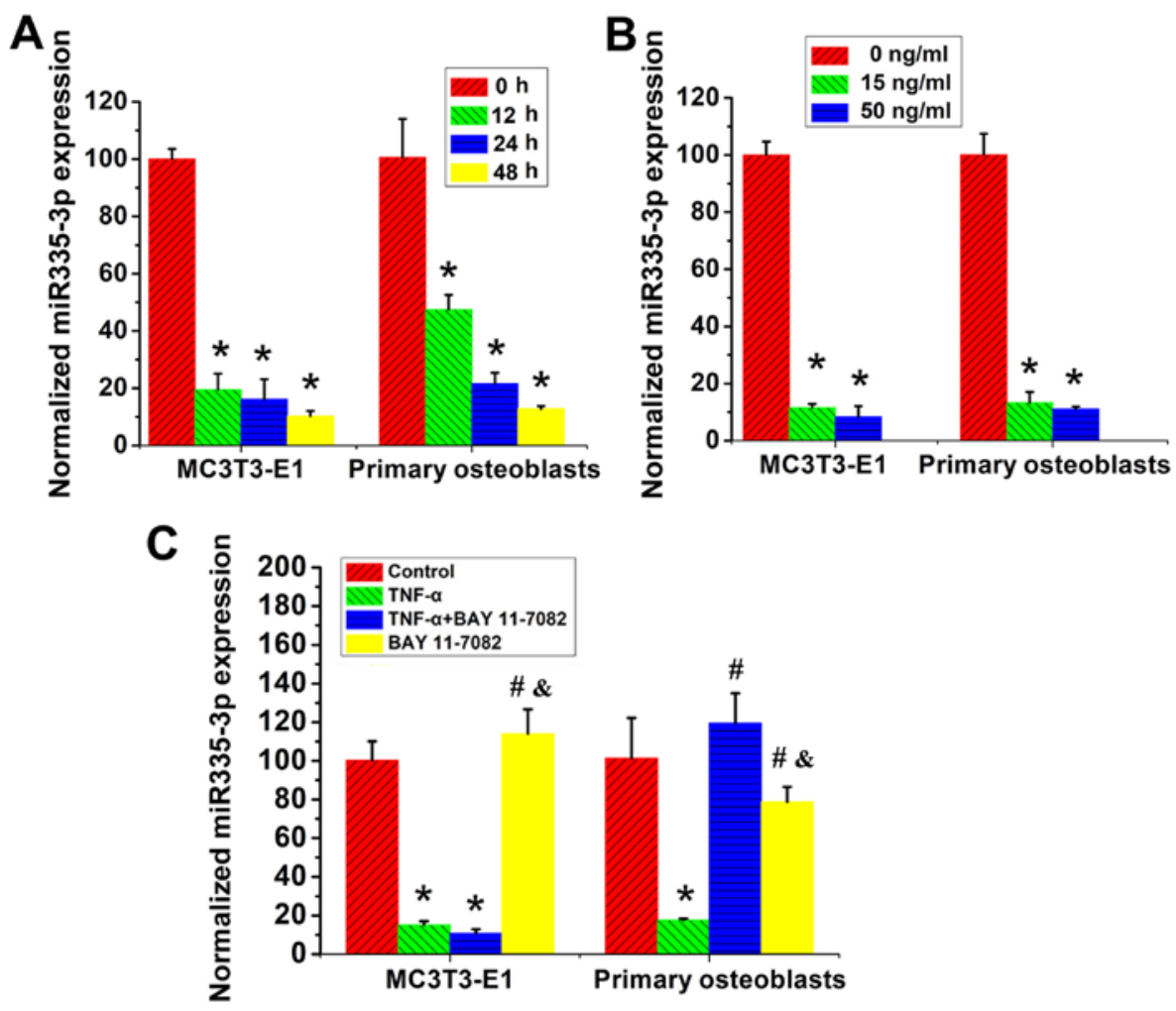

Figure 4. Effects of TNF- $\alpha$ treatment on the expression of miR-335-5p in MC3T3-E1 cells and primary calvarial osteoblasts. (A) Levels of miR-335-5p in MC3T3-E1 cells and primary calvarial osteoblasts treated with $15 \mathrm{ng} / \mathrm{ml}$ TNF- $\alpha$ for $0,12,24$ and $48 \mathrm{~h}$. "P<0.05, vs. the 0 -h group, n=3. (B) Levels of miR-335-5p in MC3T3-E1 cells and primary calvarial osteoblasts treated with 0,15 and $50 \mathrm{ng} / \mathrm{ml}$ TNF- $\alpha$ for $48 \mathrm{~h}$. ${ }^{*} \mathrm{P}<0.05 \mathrm{vs}$. the 0 -ng/ml group, $\mathrm{n}=3$. (C) MC3T3-E1 cells and primary calvarial osteoblasts were treated with $15 \mathrm{ng} / \mathrm{ml} \mathrm{TNF}-\alpha$ and/or $1 \mu \mathrm{M}$ BAY $11-7082$ for $48 \mathrm{~h}$, and the untreated cells served as controls. Levels of miR-335-5p in these cells were determined. ${ }^{\mathrm{P}}<0.05$ vs. Control group; ${ }^{*} \mathrm{P}<0.05$ vs. TNF- $\alpha$ group; ${ }^{\&} \mathrm{P}<0.05$ vs. TNF- $\alpha+\mathrm{BAY} 11-7082$ group, $\mathrm{n}=3$. TNF- $\alpha$, tumor necrosis factor- $\alpha$; miR, microRNA.

the changes in the regulatory effect of miR-335-5p on DKK1 in an inflammatory microenvironment. Due to their ability to differentiate into osteoblasts and because they are easy to manipulate, together with their homogeneity, MC3T3-E1 osteoblast-like cells have been widely used in the research on osteogenic differentiation and have provided useful information concerning the molecular mechanisms underlying the regulation of osteoblast differentiation $(27,28)$. However, established cell lines cannot truly reflect the in vivo biological characteristics. Based on these reasons, both MC3T3-E1 cells and primary calvarial cells were used in the present study.

TNF- $\alpha$ is the most potent proinflammatory cytokine ascribed to members of the TNF superfamily and has two different receptors: TNF receptor-1 (TNFR1) and TNF receptor-2 (TNFR2) $(29,30)$. TNFR2 is mainly expressed in immune cells, whereas TNFR1 is the functional receptor of TNF- $\alpha$ in both osteoblasts and osteoclasts (31). On binding to TNFR1, TNF- $\alpha$ activates the I $\kappa$ B kinase complex, which in turn initiates the activation of NF- $\mathrm{kB}$ signaling to perform various biological and pathological functions (19). Considerable research efforts have been devoted to the investigation of the molecular mechanisms underlying TNF- $\alpha$-regulated bone metabolism (32). In contrast to its effect on activating osteoclastogenesis and promoting bone loss, TNF- $\alpha$ possesses a biphasic and complicated role in the osteogenic differentiation of osteoprogenitor cells and bone formation $(33,34)$.

As a negative regulator of the canonical Wnt signaling pathway, DKK1 prevents the binding of Wnt proteins to
LRP5/6 and therefore precludes the accumulation and nuclear translocation of $\beta$-catenin (35) Evidence has also emerged indicating that DKK1 is involved in inflammation-mediated bone loss $(26,36,37)$. In TNF transgenic mice, neutralization of DKK1 using specific antibodies was revealed to protect bone from inflammatory damage (38). TNF- $\alpha$ upregulated DKK1 both in vitro and in vivo to suppress osteogenic differentiation by inhibiting the canonical Wnt signaling pathway $(22,38)$. Consistent with these findings, the present study revealed that the protein levels of DKK1 were significantly enhanced by TNF- $\alpha$ treatment in MC3T3-E1 murine osteoblast-like cells and primary calvarial osteoblasts. In MC3T3-E1 cells, the mRNA levels of DKK1 exhibited a time- and concentration-dependent decrease by the stimulation of TNF- $\alpha$. By contrast, the DKK1 mRNA levels in the primary calvarial osteoblasts were increased by TNF- $\alpha$ treatment, and the increase in the DKK1 mRNA levels after TNF- $\alpha$ treatment was more prominent compared with the DKK1 protein levels. One reason for the difference in DKK1 mRNA expression levels between these two cell types is that the transcriptional regulation of DKK1 may have been changed in MC3T3-E1 cells. Another possible reason is that MC3T3-E1 cells were isolated from the calvaria of C57BL/6 mice within $24 \mathrm{~h}$ after birth (27), while the primary calvaria osteoblasts used in the present study were isolated from 4-6-day-old C57BL/6 mice. The difference in the developmental stages may also contribute the difference in gene expression. These findings demonstrated the existence of cell-specific molecular mechanisms under- 
A

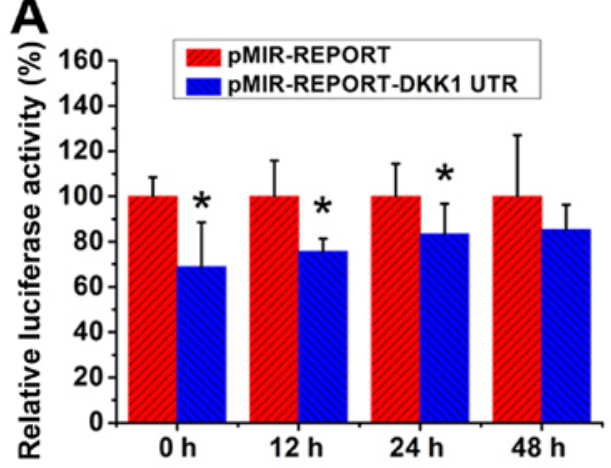

C

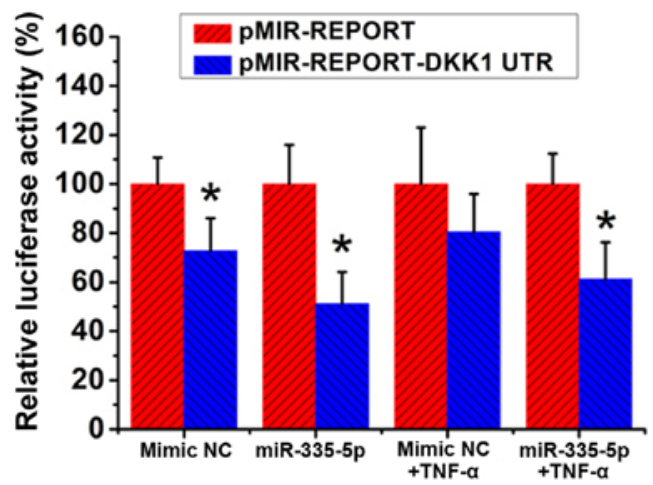

B
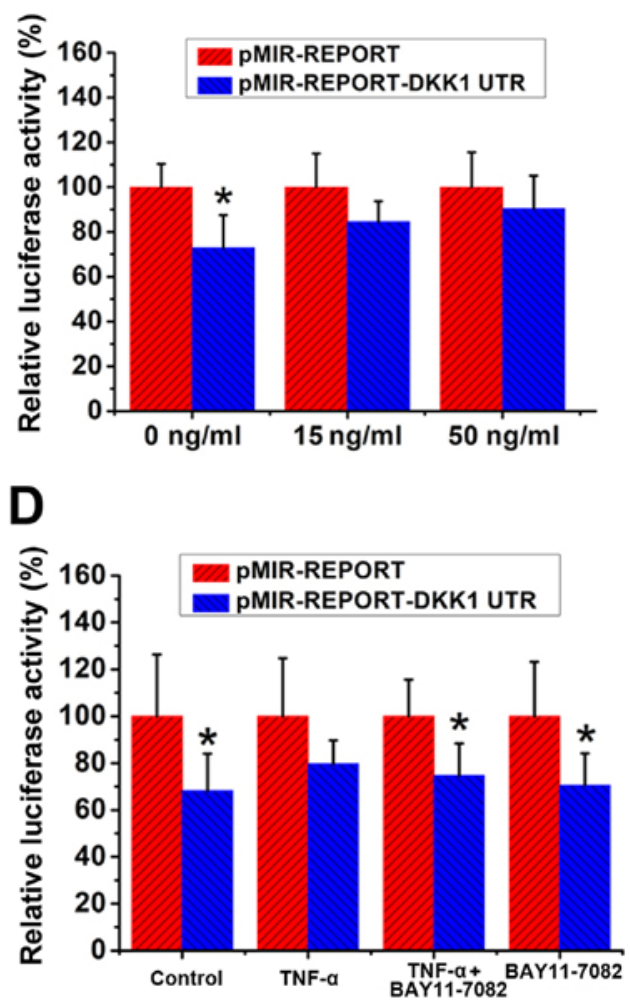

Figure 5. TNF- $\alpha$ treatment exhibits no effects on the inhibitory action of miR-335-5p via targeting of DKK1 3'UTR. MC3T3-E1 cells were co-transfected with pMIR-REPORT-DKK1 UTR and pRL-TK Vector, and cells co-transfected with pMIR-REPORT and pRL-TK served as controls. (A) Transfected MC3T3-E1 cells were treated with $15 \mathrm{ng} / \mathrm{ml} \mathrm{TNF-} \alpha$ for $0,12,24$ and $48 \mathrm{~h}$, and the luciferase levels were determined. ${ }^{*}<<0.05 \mathrm{vs}$. the pMIR-REPORT group, $\mathrm{n}=3$. (B) Transfected MC3T3-E1 cells were treated with 0,15 and $50 \mathrm{ng} / \mathrm{ml} \mathrm{TNF}-\alpha$ for $48 \mathrm{~h}$, and the luciferase levels were determined. * $\mathrm{P}<0.05$, vs. the pMIR-REPORT group, $\mathrm{n}=3$. (C) mmu-miR-335-5p mimic or mirVana ${ }^{\mathrm{TM}}$ miRNA Mimic Negative Control \#1 were transfected into the MC3T3-E1 cells concurrently, and the luciferase levels were determined. The transfected cells were treated with or without $15 \mathrm{ng} / \mathrm{ml} \mathrm{TNF}-\alpha$ for $48 \mathrm{~h}$. The luciferase levels were determined. ${ }^{*} \mathrm{P}<0.05$, vs. the pMIR-REPORT group, $\mathrm{n}=3$. mimic NC= miRNA Mimic negative Control. (D) Transfected MC3T3-E1 cells were treated with or without $15 \mathrm{ng} / \mathrm{ml}$ TNF- $\alpha$ and/or $1 \mu \mathrm{M}$ BAY $11-7082$ for $48 \mathrm{~h} .{ }^{*} \mathrm{P}<0.05$ vs. the pMIR-REPORT group, $\mathrm{n}=3$. TNF- $\alpha$, tumor necrosis factor- $\alpha$; miR, microRNA; DKK1, Dickkopf WNT signaling pathway inhibitor 1.

lying TNF- $\alpha$-regulated biological processes. In addition, the post-transcriptional regulation played an important role in the control of DKK1 protein expression in an inflammatory environment. Notably, the results of the present study revealed that the post-transcriptional regulation of the DKK1 protein expression following TNF- $\alpha$ treatment was activated in MC3T3-E1 cells, while still suppressed in the primary calvarial osteoblasts.

As a widely accepted NF-kB inhibitor, BAY 11-7082 selectively inhibits nucleotide oligomerization domain-, leucine-rich repeat- and pyrin domain-containing protein 3 (NLRP3) inflammasome activity in macrophages independent of their inhibitory effect on $\mathrm{NF}-\kappa \mathrm{B}$ activity (39). In fact, a two-step mechanism is necessary for NLRP3 activation. First, NLRP3 is transcriptionally upregulated by activated NF- $\kappa \mathrm{B}$ signaling. Second, NLRP3 is activated via stimuli such as ATP, pore-forming toxins and reactive oxygen species. Once activated, NLRP3 forms a molecular platform and recruits the adaptor protein ASC, which eventually leads to the activation of procaspase-1 and the upregulation of active pro-inflammatory cytokines interleukin (IL)-1 $\beta$ and IL-18 (39). Although NLRP3 is also affected by BAY 11-7082 treatment, it has been reported that in bone marrow mesenchymal stem cells and osteoblasts, NLRP3 acts downstream of canonical Wnt signaling and the Wnt antagonist, DKK1 (40). In addition, although activated caspase-1 by NLRP3 activation triggers pyroptosis, which is a form of cell death, changes in cell survival/proliferation/apoptosis only have limited effect on the final results in the present study due to the application of various internal controls in all experiments. Indeed, BAY 11-7082 was still used as a potent inhibitor of NF- $\mathrm{B}$ signaling in a number of studies (7-10). Based on these previous investigations, the present study also used BAY 11-7082 to inhibit TNF- $\alpha$-activated NF- $\kappa \mathrm{B}$ signaling.

BAY 11-7082 was then used to investigate the molecular mechanisms underlying TNF- $\alpha$-regulated DKK1 mRNA and protein expression. It was revealed that in both MC3T3-E1 cells and the primary calvarial osteoblasts, BAY 11-7082 partially reversed the effects of TNF- $\alpha$ on DKK1 mRNA expression, while completely reversing the effects of TNF- $\alpha$ on DKK1 protein expression. In addition to $\mathrm{NF}-\kappa \mathrm{B}$ signaling, TNF- $\alpha$ has also been demonstrated to activate p38, ERK1/2, and JNK1/2 mitogen-activated protein kinase (MAPK) signaling pathways (41). Furthermore, although TNF- $\alpha$ and BMP-2 have been revealed to activate $\mathrm{p} 38$ and ERK1/2 signaling pathways, the p38 and ERK1/2 signaling activated by TNF- $\alpha$ and BMP-2 have opposing roles in regulating osteoblastic differentiation (41). Together with these previous findings, the results of the present study indicated that in addition to the canonical $\mathrm{NF}-\kappa \mathrm{B}$ signaling, other signaling pathways such as the MAPK signaling pathways also participate in TNF- $\alpha$-induced regu- 
lation of the DKK1 mRNA expression. However, NF- $\mathrm{BB}$ signaling plays a pivotal role in TNF- $\alpha$-induced regulation of the DKK1 protein expression.

A previous study reported that miR-335-5p post-transcriptionally downregulates the protein level of DKK1 by specifically binding to the 3'UTR of the DKK1 mRNA, and thus activating Wnt signaling and promoting osteogenic differentiation in a cell- and developmental stage-specific way (13). To investigate the role of TNF- $\alpha$ in the post-transcriptional regulation of DKK1 by miR-335-5p, the expression levels of miR-335-5p upon TNF- $\alpha$ stimulation were first determined. It was revealed that in both MC3T3-E1 cells and the primary calvarial osteoblasts, the expression levels of miR-335-5p exhibited a time- and concentration-dependent decrease after TNF- $\alpha$ treatment. Further investigation revealed that inhibition of the NF- $\mathrm{kB}$ signaling via BAY 11-7082 treatment in MC3T3-E1 cells exhibited no effect on TNF- $\alpha$-mediated downregulation of miR-335-5p in these cells, demonstrating that the inhibitory effect of TNF- $\alpha$ on the expression of miR-335-5p in MC3T3-E1 cells was not mediated by NF- $\kappa B$ signaling. Considering that the positive effect of TNF- $\alpha$ on DKK1 protein expression in MC3T3-E1 cells is completely reversed by BAY 11-7082 treatment, it can be hypothesized that the decreased expression of miR-335-5p in MC3T3-E1 cells, probably induced by TNF- $\alpha$-activated MAPK signaling pathways, has limited effects on the regulation of DKK1 protein expression in these cells. By contrast, BAY 11-7082 treatment in the primary calvarial cells fully reversed the inhibitory effect of TNF- $\alpha$ on miR-335-5p expression. As aforementioned, upon BAY 11-7082 treatment the enhanced DKK1 protein expression after TNF- $\alpha$ treatment was completely reversed in the primary calvarial osteoblasts. Therefore it can be concluded that following TNF- $\alpha$ treatment, the final upregulation of DKK1 protein expression in the primary calvarial osteoblasts was not only based on the predominantly increased DKK1 mRNA level, but also the results of the compromised post-transcriptional inhibition due to, at least partly, the downregulated miR-335-5p expression.

As aforementioned, the decreased miR-335-5p level induced by TNF- $\alpha$ treatment in MC3T3-E1 cells exhibited limited positive effects on DKK1 protein levels, which contradicts a previous study revealing that miR-335-5p specifically and post-transcriptionally inhibited DKK1 protein expression (13). To investigate whether the inhibitory effect of miR-335-5p on DKK1 protein expression by binding to DKK1 $3^{\prime}$ UTR is compromised in MC3T3-E1 cells after TNF- $\alpha$ treatment, pMIR-REPORT-DKK1 UTR encoding the 3'UTR of DKK1 was transiently transfected into MC3T3-E1 cells and the changes in luciferase levels upon TNF- $\alpha$ stimulation were evaluated. It was determined that TNF- $\alpha$ treatment time- and concentration-dependently reversed the inhibitory effects of the insertion of DKK1 3'UTR. Exogenous miR-335-5p was then co-transfected with pMIR-REPORT-DKK1 UTR into the MC3T3-E1 cells. With or without TNF- $\alpha$ treatment, the exogenous miR-335-5p resulted in an additional $20 \%$ decrease in luciferase levels. These results indicated that in MC3T3-E1 cells, the binding and inhibitory effect of miR-335-5p on DKK1 3'UTR was intact following TNF- $\alpha$ treatment. In addition, the effect of TNF- $\alpha$ treatment on DKK1 3'UTR was mainly achieved by regulating the expression levels of endogenous
miRNAs specifically targeting DKK1 3'UTR. Further studies should be performed to investigate the mechanisms underlying the compromised inhibitory effect of miR-335-5p on DKK1 expression in MC3T3-E1 cells after TNF- $\alpha$ treatment.

In conclusion, although TNF- $\alpha$ treatment exhibited cell-specific effects on DKK1 mRNA expression, the stimulation of TNF- $\alpha$ time- and concentration-dependently upregulated the protein levels of DKK1, indicating the important role of post-transcriptional regulation during this biological process. In the primary calvarial osteoblasts, the predominantly increased DKK1 mRNA level and the compromised post-transcriptional inhibition by specific miRNAs such as miR-335-5p both participated in the enhanced expression of DKK1 induced by TNF- $\alpha$ treatment. By contrast, the post-transcriptional regulation served a pivotal role in TNF- $\alpha$-stimulated DKK1 expression in MC3T3-E1 cells; the molecular mechanisms underlying this post-transcriptional regulation is more complex and requires further investigation in the future. The results of the present study provide insight into the molecular mechanisms underlying osteogenic differentiation in bone-related inflammatory diseases. Furthermore, they could aid researchers in finding a potential pharmaceutical target to treat bone-related inflammatory diseases.

\section{Acknowledgements}

Not applicable.

\section{Funding}

This work was supported by Medical and Health Science and Technology Development Project of Shandong Province (grant no. 2018WSA01018) and the Dean's Research Assistance Foundation of Ji Nan Stomatology Hospital (grant no. 2018-02).

\section{Availability of data and materials}

All data generated or analyzed during this study are included in this published article.

\section{Authors' contributions}

SL performed most of the experiments, collected and analyzed the data, and prepared the figures. YY, LY, ZL and SS performed some of the experiments. JZ provided advice on experimental design and revised the manuscript for intellectual content. XL designed the experiments, interpreted the experimental results, and drafted the manuscript. All authors read and approved the final version of the manuscript.

\section{Ethics approval and consent to participate}

Ethical approval for the animal experiments was obtained by The Medical Ethics Committee of the School of Stomatology, Shandong University (protocol no. 20180602).

\section{Patient consent of publication}

Not applicable. 


\section{Competing interests}

The authors declare that they have no competing interests.

\section{References}

1. Taurog JD, Chhabra A and Colbert RA: Ankylosing spondylitis and axial spondyloarthritis. N Engl J Med 374: 2563-2574, 2016.

2. Wu X, Gu Q, Chen X, Mi W, Wu T and Huang H: MiR-27a targets DKK2 and SFRP1 to promote reosseointegration in the regenerative treatment of peri-implantitis. J Bone Miner Res 34 123-134, 2019

3. Yang N, Wang G, Hu C, Shi Y, Liao L, Shi S, Cai Y, Cheng S, Wang X, Liu Y, et al: Tumor necrosis factor $\alpha$ suppresses the mesenchymal stem cell osteogenesis promoter miR-21 in estrogen deficiency-induced osteoporosis. J Bone Miner Res 28 : 559-573, 2013

4. Magrey MN and Khan MA: The paradox of bone formation and bone loss in ankylosing spondylitis: Evolving new concepts of bone formation and future trends in management. Curr Rheumatol Rep 19: 17, 2017.

5. Weitzmann MN: Bone and the immune system. Toxicol Pathol 45: 911-924, 2017.

6. Sun SC, Chang JH and Jin J: Regulation of nuclear factor- $\kappa \mathrm{B}$ in autoimmunity. Trends Immunol 34: 282-289, 2013

7. Litke JL and Jaffrey SR: Highly efficient expression of circular RNA aptamers in cells using autocatalytic transcripts. Nat Biotechnol 37: 667-675, 2019.

8. Keller SA, Schattner EJ and Cesarman E: Inhibition of NF-kappaB induces apoptosis of KSHV-infected primary effusion lymphoma cells. Blood 96: 2537-2542, 2000.

9. Kunkemoeller B, Bancroft T, Xing H, Morris AH, Luciano AK Wu J, Fernandez-Hernando $C$ and Kyriakides TR: Elevated thrombospondin 2 contributes to delayed wound healing in diabetes. Diabetes 68: 2016-2023, 2019.

10. Salahuddin S, Fath EK, Biel N, Ray A, Moss CR, Patel A, Patel S, Hilding L, Varn M, Ross T, et al: Epstein-barr virus latent membrane protein-1 induces the expression of SUMO-1 and SUMO-2/3 in LMP1-positive lymphomas and cells. Sci Rep 9: 208, 2019.

11. Osta B, Benedetti G and Miossec P: Classical and paradoxical effects of TNF- $\alpha$ on bone homeostasis. Front Immunol 5: 48, 2014.

12. Guo $X$ and Wang XF: Signaling cross-talk between TGF-beta/BMP and other pathways. Cell Res 19: 71-88, 2009.

13. Zhang J, Tu Q, Bonewald LF, He X, Stein G, Lian J and Chen J: Effects of miR-335-5p in modulating osteogenic differentiation by specifically downregulating Wnt antagonist DKK1. J Bone Miner Res 26: 1953-1963, 2011.

14. Maeda Y, Farina NH, Matzelle MM, Fanning PJ, Lian JB and Gravallese EM: Synovium-derived MicroRNAs regulate bone pathways in rheumatoid arthritis. J Bone Miner Res 32: 461-472, 2017.

15. Sang C, Zhang Y, Chen F, Huang P, Qi J, Wang P, Zhou Q, Kang H, Cao $\mathrm{X}$ and Guo L: Tumor necrosis factor alpha suppresses osteogenic differentiation of MSCs by inhibiting semaphorin $3 \mathrm{~B}$ via $\mathrm{Wnt} / \beta$-catenin signaling in estrogen-deficiency induced osteoporosis. Bone 84: 78-87, 2016.

16. Diarra D, Stolina M, Polzer K, Zwerina J, Ominsky MS, Dwyer D, Korb A, Smolen J, Hoffmann M, Scheinecker C, et al: Dickkopf-1 is a master regulator of joint remodeling. Nat Med 13: 156-163, 2007.

17. Pritchard CC, Cheng HH and Tewari M: MicroRNA profiling: Approaches and considerations. Nat Rev Genet 13: 358-369, 2012.

18. Hassan MQ, Maeda Y, Taipaleenmaki H, Zhang W, Jafferji M, Gordon JA, Li Z, Croce CM, van Wijnen AJ, Stein JL, et al: miR-218 directs a Wnt signaling circuit to promote differentiation of osteoblasts and osteomimicry of metastatic cancer cells. J Biol Chem 287: 42084-42092, 2012.

19. Wang W, Yang L, Zhang D, Gao C, Wu J, Zhu Y and Zhang $\mathrm{H}$ : MicroRNA-218 negatively regulates osteoclastogenic differentiation by repressing the nuclear factor- $\kappa \mathrm{B}$ signaling pathway and targeting tumor necrosis factor receptor 1. Cell Physiol Biochem 48: 339-347, 2018.

20. Deng L, Hu G, Jin L, Wang $\mathrm{C}$ and Niu $\mathrm{H}$ : Involvement of microRNA-23b in TNF-alpha-reduced BMSC osteogenic differentiation via targeting runx2. J Bone Miner Metab 36: 648-660, 2018.
21. Mi W, Shi Q, Chen X, Wu T and Huang H: miR-33a-5p modulates TNF-alpha-inhibited osteogenic differentiation by targeting SATB2 expression in hBMSCs. FEBS Lett 590: 396-407, 2016.

22. Li C, Zhang P and Gu J: miR-29a modulates tumor necrosis factor- $\alpha$-induced osteogenic inhibition by targeting Wnt antagonists. Dev Growth Differ 57: 264-273, 2015.

23. Sui L, Wang M, Han Q, Yu L, Zhang L, Zheng L, Lian J, Zhang J, Valverde P, Xu Q, et al: A novel Lipidoid-MicroRNA formulation promotes calvarial bone regeneration. Biomaterials 177: 88-97, 2018.

24. Livak KJ and Schmittgen TD: Analysis of relative gene expression data using real-time quantitative PCR and the 2(-Delta Delta C(T)) method. Methods 25: 402-408, 2001

25. Matzelle MM, Gallant MA, Condon KW, Walsh NC, Manning CA, Stein GS, Lian J B, Burr DB and Gravallese EM: Resolution of inflammation induces osteoblast function and regulates the Wnt signaling pathway. Arthritis Rheum 64: 1540-1550, 2012.

26. Walsh NC and Gravallese EM: Bone remodeling in rheumatic disease: A question of balance. Immunol Rev 233: 301-312, 2010.

27. Quarles LD, Yohay DA, Lever LW, Caton R and Wenstrup RJ: Distinct proliferative and differentiated stages of murine MC3T3-E1 cells in culture: An in vitro model of osteoblast development. J Bone Miner Res 7: 683-692, 1992.

28. Arriero Mdel M, Ramis JM, Perelló J and Monjo M: Differential response of MC3T3-E1 and human mesenchymal stem cells to inositol hexakisphosphate. Cell Physiol Biochem 30: 974-986, 2012.

29. Naismith JH and Sprang SR: Tumor necrosis factor receptor superfamily. J Inflamm 47: 1-7, 1995.

30. Idriss HT and Naismith JH: TNF alpha and the TNF receptor superfamily: Structure-function relationship(s). Microsc Res Tech 50: 184-195, 2000.

31. Huang H, Zhao N, Xu X, Xu Y, Li S, Zhang J and Yang P: Dose-specific effects of tumor necrosis factor alpha on osteogenic differentiation of mesenchymal stem cells. Cell Prolif 44: 420-427, 2011.

32. Zhao B: TNF and bone remodeling. Curr Osteoporos Rep 15 126-134, 2017.

33. Wang L, Zhang J, Wang C, Qi Y, Du M, Liu W, Yang C and Yang P: Low concentrations of TNF- $\alpha$ promote osteogenic differentiation via activation of the ephrinB2-EphB4 signalling pathway. Cell Prolif 50: e12311,2017.

34. Karnes JM, Daffner SD and Watkins CM: Multiple roles of tumor necrosis factor-alpha in fracture healing. Bone 78: 87-93, 2015.

35. Wang FS, Chuang PC, Lin CL, Chen MW, Ke HJ, Chang YH, Chen YS, Wu SL and Ko JY: MicroRNA-29a protects against glucocorticoid-induced bone loss and fragility in rats by orchestrating bone acquisition and resorption. Arthritis Rheum 65: 1530-1540, 2013

36. Redlich K and Smolen JS: Inflammatory bone loss: Pathogenesis and therapeutic intervention. Nat Rev Drug Discov 11: 234-250, 2012.

37. Jing Y, Feng J ZH, Zhao X, Yang J, Bai D and Han X: Role of DKK1 in periodontitis and innovative strategy with its neutralizing antibody for periodontitis treatment. OHDM 13: 994-997, 2014

38. Heiland GR, Zwerina K, Baum W, Kireva T, Distler JH, Grisanti M, Asuncion F, Li X, Ominsky M, Richards W, et al: Neutralisation of Dkk-1 protects from systemic bone loss during inflammation and reduces sclerostin expression. Ann Rheum Dis 69: 2152-2159, 2010

39. Juliana C, Fernandes-Alnemri T, Wu J, Datta P, Solorzano L, Yu JW, Meng R, Quong AA, Latz E, Scott CP and Alnemri ES: Anti-inflammatory compounds parthenolide and Bay 11-7082 are direct inhibitors of the inflammasome. J Biol Chem 285: 9792-9802, 2010

40. Xu L, Zhang L, Wang Z, Li C, Li S, Li L, Fan Q and Zheng L: Melatonin suppresses estrogen deficiency-induced osteoporosis and promotes osteoblastogenesis by inactivating the NLRP3 inflammasome. Calcif Tissue Int 103: 400-410, 2018

41. Huang RL, Yuan Y, Tu J, Zou GM and Li Q: Opposing TNF- $\alpha /$ IL-1 $\beta$ - and BMP-2-activated MAPK signaling pathways converge on Runx2 to regulate BMP-2-induced osteoblastic differentiation. Cell Death Dis 5: e1187, 2014.

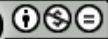

This work is licensed under a Creative Commons Attribution-NonCommercial-NoDerivatives 4.0 International (CC BY-NC-ND 4.0) License. 